\title{
Pedagogia: para quê? Desafios contemporâneos à formação para afirmação da diversidade humana
}

\author{
Pedagogy: for what? Contemporary challenges to training representation \\ of human diversity
}

\author{
Pedagogía: para quéci Desafios a la representación de la diversidad \\ y formación humana
}

\author{
ANDRESSA SILVA PEREIRA* \\ ALAN ROCHA DAMASCENO**
}

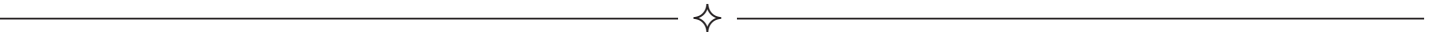

RESUMO

O movimento atual da educação inclusiva considera essencial a todos os(as) estudantes a experiência do convívio das diferenças no mesmo espaço escolar, sendo possível assumir como centralidade do trabalho pedagógico as diferenças humanas. Quanto a isso, é importante ressalvar que a formação do(a) pedagogo(a) se encontra diante desse desafio. Este artigo tem por objetivo refletir sobre os impactos das atuais políticas públicas de educação inclusiva no âmbito da modalidade Educação Especial, nos cursos de licenciatura em Pedagogia, na contemporaneidade, a fim de contribuir para a possibilidade de emancipação e autorreflexão crítica da diversidade humana.
\end{abstract}

Palavras-chave: Educação inclusiva. Educação Especial. Formação do(a) pedagogo(a).

\begin{abstract}
The current movement of inclusive education considers that it is essential for all students to experience the existence of differences in the same school space, and it is possible to assume the centrality of pedagogical work to human differences. In this regard, it is important to consider that the education of the pedagogue is faced with this challenge. This article aims to reflect on the impacts of the current public policies of inclusive education within the scope of the Special Education modality in undergraduate courses in Pedagogy in the contemporaneity, in order to contribute to the possibility of emancipation and critical self - reflection of human diversity.
\end{abstract}

Keywords: Inclusive education. Special Education. Teacher training(a).

\section{RESUMEN}

El movimiento actual de la educación inclusiva considera esencial para todos los / las estudiantes a experimentar la convivencia de las diferencias en el mismo espacio de la escuela, y se puede tomar como la importancia de las diferencias humanas de trabajo docente. En este sentido, es importante que la formación del / la maestro / a se enfrenta a este reto. Este artículo tiene como objetivo reflexionar sobre los impactos de las políticas públicas actuales de la educación inclusiva dentro de la modalidad de Educación Especial en los cursos de licenciatura en Pedagogía en la época contemporánea, con el fin de contribuir a la posibilidad de emancipación y auto-reflexión crítica de la diversidad humana.

Palabras clave: Educación inclusiva. Educación Especial. Formación de maestros(as).

\footnotetext{
*Pedagoga e Mestre em Educação pelo Programa de Pós-graduação em Educação, Contextos Contemporâneos e Demandas Populares (PPGEduc/UFRRJ). E-mail: <andressasp07@hotmail.com>.

**Professor Adjunto do Instituto de Educação da Universidade Federal Rural do Rio de Janeiro/UFRRJ. Atua no Programa de Pós-graduação em Educação, Contextos Contemporâneos e Demandas Populares (PPGEduc/UFRRJ) e no Programa de Pós-graduação em Educação Agrícola (PPGEA/UFRRJ). Atual Coordenador do Curso de Pedagogia (Campus Seropédica) da Universidade Federal Rural do Rio de Janeiro/UFRRJ.E-mail: <lepedi-ufrrj@hotmail.com>.
} 


\section{INTRODUÇÃO}

O debate acerca da diversidade nas escolas, e em várias instâncias da sociedade, tem sido caracterizado por metamorfoses constantes na esfera social, econômica e política, e aprofundado pela globalização, marcada pela sociedade do conhecimento e pelo ritmo de produção do capital. Este momento é de renovação das ideias, considerando-se a pluralidade na construção do saber entre as diversas culturas na sociedade, com base no respeito pela diferença. Este, por sua vez, concretiza-se no reconhecimento da paridade dos direitos em tempos de educação inclusiva. Nesse sentido, Libâneo e Pimenta (2006, p. 32) ressaltam que:

\begin{abstract}
Assim, reivindica-se, com toda a legitimidade, a presença atuante de profissionais dotados de capacitação pedagógica para atuarem nas mais diversas instituições e ambientes da comunidade: nos movimentos sociais, nos meios de comunicação de massa, nas empresas, nos hospitais, nos presídios, nos projetos culturais e nos programas comunitários de melhoria da qualidade de vida. Esta participação pedagógica também exige preparação prévia, sistemática e qualificada [...] O entendimento de que os profissionais da educação formados pelo curso de pedagogia atuarão nos vários campos sociais da educação, decorrentes de novas necessidades e demandas sociais a serem regulados profissionalmente.
\end{abstract}

Dessa forma, a universidade, como um todo orgânico, deve se dedicar à tarefa de pensar e reformular constantemente seu papel como mediadora no processo de formação dos profissionais da educação no curso de graduação em Pedagogia, com um ensino voltado para a diversidade da população brasileira. Configurando esse princípio, as Diretrizes Curriculares Nacionais (DCNs) para o Curso de Pedagogia (BRASIL, 2006) afirmam que:

$\mathrm{Na}$ organização curricular do curso de Pedagogia [...] deverão ser observados, com especial atenção, os princípios constitucionais e legais; a diversidade social, étnico-racial e regional do País; a organização federativa do Estado brasileiro; a pluralidade de ideias e concepções pedagógicas; o conjunto de competências dos estabelecimentos de ensino e dos docentes, previstas nos arts. 12 e 13 da Lei de Diretrizes e Bases da Educação Nacional (Lei no 9.394/1996) e o princípio da gestão democrática e da autonomia [...] no sentido de que a formação de professores, nas suas fases inicial e continuada, contemple a educação dos cidadãos(ãs), tendo em vista uma ação norteada pela ética, justiça, dialogicidade, respeito mútuo, solidariedade, tolerância, reconhecimento da diversidade, valorização das diferentes culturas, e suas repercussões na vida social, de modo particular nas escolas, dando-se especial atenção à educação das relações de gênero, das relações étnico-raciais, à educação sexual, à preservação do meio ambiente articuladamente à da saúde e da vida, além de outras questões de relevância local, regional, nacional e até mesmo internacional.

Além disso, um dos artigos das referidas DCNs do curso de Pedagogia, determina que:

Art. 5o O egresso do curso de Pedagogia deverá estar apto a:

$[\ldots]$

IX -identificar problemas socioculturais e educacionais com postura investigativa, integrativa e propositiva em face de realidades complexas, com vistas a contribuir para superação de exclusões sociais, étnico-raciais, econômicas, culturais, religiosas, políticas e outras;

$\mathrm{X}$ - demonstrar consciência da diversidade, respeitando as diferenças de natureza ambiental-ecológica, étnicoracial, de gêneros, faixas geracionais, classes sociais, religiões, necessidades especiais, escolhas sexuais, entre outras;

Art. $6^{\circ}$ A estrutura do curso de Pedagogia, respeitadas a diversidade nacional e a autonomia pedagógica das instituições, constituir-se-á de:

I - um núcleo de estudos básicos que, sem perder de vista a diversidade e a multiculturalidade da sociedade brasileira, por meio do estudo acurado da literatura pertinente e de realidades educacionais, assim como por meio de reflexão e ações críticas, articulará:

[...]

d) utilização de conhecimento multidimensional sobre o ser humano, em situações de aprendizagem.

Considerando os saberes e fazeres dos egressos do curso de Pedagogia, traz-se ao debate a seguinte previsão das Diretrizes Nacionais de Educação Especial na Educação Básica (2001, p. 42):

[...] a inclusão postula uma reestruturação do sistema educacional, ou seja, uma mudança estrutural no ensino regular cujo objetivo é fazer com que a escola se torne inclusiva, um espaço democrático e competente para trabalhar com todos os educandos, sem distinção de raça, classe, gênero, ou características pessoais, baseando-se no princípio de que a diversidade não deve ser só aceita como também desejada.

Essas perspectivas legais configuram uma educação para a alteridade, para a equidade de oportunidades e para a atenção aos direitos. A formação do(a) pedagogo(a) há de ser constituída numa dimensão pluricultural, em que as abordagens curriculares e didáticas sejam pautadas na superação dos preconceitos, na afirmação de direitos humanos e no pluralismo de ideias/concepções. Nesse sentido, é importante que a educação efetive o direito à 
diferença, baseado na práxis do respeito e da equiparação de oportunidades. Sobre esse aspecto, Barreto (2009, p. 182) acrescenta que:

Uma proposta curricular na atualidade requer, assim, que o professor da escola inclusiva saiba buscar o específico no geral, na totalidade do saber construído e historicamente socializado. Sua formação dar-se-á em permanente embate da teoria com sua prática pedagógica, com a extensão e a pesquisa daí decorrente. Como tal, deve ser pensada no bojo das reformulações que vêm sendo implementadas nos cursos de pedagogia, concebendo o trabalho do professor intencionalmente dirigido para a formação humana, por meio de conteúdos e habilidades de pensamento e ação, implicando escolhas, valores e compromissos éticos vinculados a processos metodológicos e organizacionais.

Daí a importância de se refletir sobre a formação do pedagogo/professor como agente de transformação nas instâncias sociais e escolares e na constituição de uma "consciência verdadeira", que segundo Adorno (1995) se contrapõe e resiste à força da dominação. Nesse aspecto, Damasceno (2015, p. 23-24) ressalta que:

[...] esse momento histórico da educação no Brasil evidencia a singularidade de se viver a organização da escola democrática, na qual as diferenças dos estudantes sejam estímulo para os professores desenvolverem novos métodos/estratégias/meios de ensino para permitir a aprendizagem de todos. [...] Tal discussão destaca-se no debate nas universidades e escolas públicas, uma vez que as mudanças a serem promovidas no sistema educacional demandam esforços, como adaptações arquitetônicas, didáticopedagógicas e curriculares, tecnologias assistivas, entre outros.

Essa formação voltada para os profissionais da educação - pedagogos(as) nos cursos de graduação/ licenciatura em Pedagogia - necessita criar alternativas cujas ações pedagógicas impactem para além do contexto escolar, sobretudo a constituição de saberes e fazeres que propiciem uma forma de práxis desalienada. Isto é, um conhecimento crítico em que se dá a ação. É importante ressalvar que se corre o risco de absolutizar o relativo trabalho -, sem, contudo, pensar-se no concreto - aquilo que está presente em seu fazer pedagógico. Mitificando-o e passando, assim, para a alienação, além de transformar o fazer na mera execução, ou seja, numa prática ativista que gera ações mecanicistas. De acordo com o pensamento de Adorno (1995, p. 144):

A adaptação não deve conduzir à perda da individualidade em um conformismo uniformiza-dor.
Esta tarefa é tão complicada porque precisamos nos libertar de um sistema educacional referido apenas ao indivíduo. Mas, por outro lado, não devemos permitir uma educação sustentada na crença de poder eliminar o indivíduo.

A consciência precisa ter a experiência do "eu reflexivo", do "tornar-se" e "estar sendo" na dinâmica social, que por sua vez é frenada pelo "processo de coisificação", o que contribui para o desenvolvimento do pensamento conservador, obstaculizando/impedindo a experiência da autorreflexão. Conforme destaca Adorno (1995a, p. 203-204):

O que, desde então, vale como o problema da práxis, e hoje novamente se agrava na questão da relação entre teoria e práxis, coincide com a perda de experiência causada pela racionalidade do sempre-igual. Onde a experiência é bloqueada ou simplesmente já não existe, a práxis é danificada e, por isso, ansiada, desfigurada, desesperadamente supervalorizada. Assim, o chamado problema da práxis está entrelaçado com o do conhecimento.

Em vista disso, é crescente a demanda por um currículo que integre as concepções da diversidade brasileira, com destaque nesse estudo a modalidade Educação Especial nas universidades públicas, no intuito de formar profissionais da educação nos cursos de Licenciatura em Pedagogia. E para que estes venham a atender esses estudantes nas escolas públicas de ensino regular, pois a diversidade e a diferença precisam ser entendidas no contexto da educação contemporânea como possibilidades humanas que enriquecem as experiências pedagógicas. Nesse sentido, Adorno (1995, p. 141-142) esclarece:

[...] Em relação a esta questão, gostaria apenas de atentar a um momento específico no conceito de modelo ideal, o da heteronomia, o momento autoritário, o que é imposto a partir do exterior. Nele existe algo de usurpatório [...] Numa democracia, quem defende ideais contrários à emancipação, e, portanto, contrários à decisão consciente independente de cada pessoa em particular, é um antidemocrata, até mesmo ideias que correspondem a seus desígnios são difundidas no plano formal da democracia.

Assim, destaca-se a importância sobre questões que se inserem nos princípios e práticas do processo de inclusão, que garantam o direito e o acesso à educação e considerem a diversidade humana em suas diversas expressões: social, cultural, econômica, de gênero, de raça, de etnia, dos indígenas, das pessoas com deficiência, das populações do campo, de diferentes orientações 
sexuais, de sujeitos de rua, dos que estão em privação de liberdade e de todos que compõem a plural sociedade brasileira. Quanto a isso, esclarece Peças (2003, p. 143):

A educação inclusiva não é um conceito restrito à racionalidade pedagógica. A educação inclusiva inspira-se no substracto transdisciplinar aos mais recentes contributos das várias ciências e visa à sociedade inclusiva. A sua construção, que é um processo permanente, implica os mais amplos espaços sociais e culturais e apela a mais vasta participação das comunidades sociais e científicas.

Daí a importância da educação inclusiva, que por intermédio das políticas públicas promove o reconhecimento dos direitos dos indivíduos a uma educação plural, solidária e humana. A formação do(a) pedagogo(a) não é uma ação isolada desses princípios globalizantes, desconsiderando os outros segmentos da sociedade (pessoas com deficiência, negros, indígenas, população do campo, entre outros). As ações pedagógicas nas instituições, tanto da educação básica quanto do ensino superior, não podem ser demarcadas apenas por intenções, mas precisam ser substanciadas pelas ações em diversos setores e contextos micro e macro da sociedade. Assim, verifica-se que:

Os sistemas educativos devem orientar-se no sentido de estarem em condições de gerar as aptidões e competências de base necessárias a todos na sociedade da informação, tornar a educação e a formação ao longo da vida atraente e gratificante, dirigir-se a toda a sociedade, na sua diversidade, mesmo àqueles que consideram que a educação e a formação não lhes interessam, com os instrumentos susceptíveis de desenvolver as respectivas competências e de as explorar da melhor maneira (CONSELHO NACIONAL DE EDUCAÇÃO, 2002, p. 02).

Desse modo, ao se refletir sobre a formação do(a) pedagogo(a) nos cursos de Pedagogia, no âmbito da modalidade Educação Especial, considerando os diferentes contextos epistemológicos, políticos e filosóficos das instituições de ensino superior, considera-se a indissociabilidade da crítica à transformação do conhecimento. Quanto a isso, Adorno (1996, p. 392) afirma que: "[...] quando mais lúcido os singulares, mais lúcido o todo".

\section{DeSENVOLVIMENTO}

\section{Metodologia}

A pesquisa assume como proposta a perspectiva da teoria crítica da sociedade, com destaque para o pensamento de Theodor Adorno, filósofo da Escola da
Teoria Crítica, além de outros autores como suporte teórico-metodológico.Cabe ressaltar que para a teoria crítica da sociedade não existe cisão entre teoria e método. Portanto, considerando essa proposta teóricometodológica, a própria teoria é o método do estudo.

Nesse sentido, não há como qualificar o presente trabalho como uma pesquisa quantitativa ou qualitativa, pois para a teoria crítica seria "aprisionar" o objeto de estudo. Para essa abordagem, a práxis e a teoria são um binômio, "partindo da Teoria para entender a Práxis, retornando à primeira para construir conhecimento [...] uma vez que Práxis e Conhecimento são indissociáveis" (DAMASCENO, 2010, p. 127). Sobre esse aspecto, Adorno (1995a, p. 204-205) esclarece:

Dever-se-ia formar uma consciência de teoria e práxis que não separasse ambas de modo que a teoria fosse impotente e a práxis arbitrária, nem destruísse a teoria mediante o primado da razão prática, próprio dos primeiros tempos da burguesia e proclamado por Kant e Fichte. Pensar é um agir, teoria é uma forma de práxis; somente a ideologia da pureza do pensamento mistifica este ponto. O pensar tem um duplo caráter: é imanentemente determinado, estringente e obrigatório em si mesmo. Mas, ao mesmo tempo, é um modo de comportamento irrecusavelmente real em meio à realidade. Na medida em que o sujeito, a substância pensante dos filósofos, é objeto, na medida em que incide no objeto, nessa medida, ele é, de antemão, também prático.

O pensamento de Adorno propõe a reflexão sobre a importância de analisar a práxis substanciada nas relações teoria-reflexão e prática-ação, pois a prática sem a teoria é estéril e a teoria sem a prática é inócua. Nessa perspectiva, a relação teoria-práxis é proposta no sentido de construção objeto-meio, a fim de que seja vista como um campo de possibilidades em definir e avaliar a natureza ao que está empiricamente dado. Pois "definir é o mesmo que capturar - objetividade, mediante o conceito fixado, algo objetivo, não importa o que isto seja em si" (ADORNO, 1995a, p. 182).

Nessa perspectiva, é ir além da naturalização das ideias, fazendo com que a teoria-práxis- seja refletida com a objetividade crítica, além de permitir que a construção do conhecimento não seja "dissolvida" em uma ideologia marcada pela falsa racionalidade que pode "alienar" o próprio objeto de estudo. Isso porque, sem uma base consolidada na experiência, é impossível erigir uma qualificação no nível da reflexão. Para a teoria crítica, pensar é o mesmo que fazer/viver experiências em sua finalidade humana. Logo, "a teoria foi desenvolvida para lutar contra o consenso como forma de questionar a dominação e criar o impulso de lutar contra ela" (SANTOS, 1999, p. 212). 
Ante as reflexões, considerando a concepção da escolha metodológica à luz da teoria crítica, este estudo fundamenta-se na análise documental, assumida como procedimento de coleta de dados. Analisa as diretrizes políticas da Educação Especial na perspectiva da educação inclusiva (BRASIL, 2008), entre outros marcos regulatórios da Educação Especial, e as Diretrizes Curriculares Nacionais para o curso de Pedagogia (BRASIL, 2006).

\section{A formação dos professores na/para a diversidade: desafios e possibilidades}

No mundo atual, tendo em conta as demandas que envolvem a sociedade na dimensão estrutural das culturas, da economia, da diversidade humana, é importante refletir sobre a formação dos professores nos cursos de Pedagogia. O que implica uma redefinição das competências atribuídas ao licenciando na contemporaneidade, com vistas à inclusão dos estudantes ${ }^{1}$ público-alvo da Educação Especial. Em face disso, Figueiredo (2011, p. 141) aponta:

\begin{abstract}
A formação inicial, bem como a formação continuada de professores visando a inclusão de todos os alunos e o acesso deles ao ensino superior, precisa levar em conta princípios de base que os instrumentalizem para a organização do ensino e a gestão de classe, bem como princípios éticos, políticos e filosóficos que permitam a esses profissionais compreenderem o papel deles e da escola frente ao desafio de formar uma nova geração capaz de responder às demandas do nosso século.
\end{abstract}

Além disso, as Diretrizes Curriculares Nacionais para o Curso de Pedagogia (BRASIL, 2006, p. 12-13) também enfatizam tal formação para a:

[...] importância desses profissionais conhecerem as políticas de educação inclusiva e compreenderem suas implicações organizacionais e pedagógicas, para a democratização da Educação Básica no país. A inclusão não é uma modalidade, mas um princípio do trabalho educativo [...] Inclusão e atenção às necessidades educacionais especiais são exigências constitutivas da educação escolar, como um todo (grifos do autor).

Isso exige que o professor seja capaz de organizar suas práticas pedagógicas levando em conta a diversidade, o que por sua vez (re)orienta os princípios educacionais adaptados às necessidades reais dos estudantes, consolidando aprendizagens significativas no âmbito

\footnotetext{
${ }^{1}$ O público-alvo da educação especial, considerando a legislação vigente da LDBEN no 9394/96 e a Resolução no 4, de outubro de 2009, é composto por alunos com deficiência, transtornos globais do desenvolvimento e altas habilidades ou superdotação.
}

escolar. Também é válido destacar outros documentos oficiais, nacionais e internacionais, considerando a formação de professores para a diversidade humana e social, na inclusão de todos os indivíduos, inclusive os que têm deficiências nas escolas públicas regulares. No que tange a essa questão, destacam-se alguns documentos:

$\checkmark$ A Declaração de Salamanca/1994, que adverte em seu trecho sobre a formação que "a capacitação de professores especializados deverá ser reexaminada, com vistas a lhes permitir o trabalho em diferentes contextos e o desempenho de um papel-chave nos programas relativos às necessidades educativas especiais $[\ldots]$ que abranja todos os tipos de deficiências, antes de se especializar numa ou várias categorias particulares de deficiência" (p. 38).

$\checkmark$ A Lei no 9.394/1996, que estabelece as Diretrizes e Bases da Educação Nacional e determina, em seu capítulo $\mathrm{V}$, quanto à formação de professores para a Educação Especial através do (Art. 59, Inciso III), que os professores deverão ter "especialização adequada em nível médio ou superior para atendimento especializado, bem como os professores do ensino regular capacitados para a integração desses educandos nas classes comuns".

$\checkmark$ O Plano Nacional de Educação, aprovado pela Lei $\mathrm{n}$ - 13.005/2014, que dispõe sobre a formação dos profissionais da educação na meta 4.16, a qual recomenda "incentivar a inclusão nos cursos de licenciatura e nos demais cursos de formação para profissionais da educação, inclusive em nível de pós-graduação, observado o disposto no caput do art. 207 da Constituição Federal, dos referenciais teóricos, das teorias de aprendizagem e dos processos de ensino-aprendizagem relacionados ao atendimento educacional de alunos com deficiência, transtornos globais do desenvolvimento e altas habilidades ou superdotação" (p. 69).

$\checkmark$ As Diretrizes Nacionais para a Educação Especial na Educação Básica de 2001, as quais afirmam que “[...] são considerados professores especializados em Educação Especial aqueles que desenvolveram competências para identificar as necessidades educacionais especiais, definir e implementar respostas educativas a essas necessidades, apoiar o professor da classe comum, atuar nos processos de desenvolvimento e aprendizagem dos alunos, desenvolvendo estratégias de flexibilização, adaptação curricular e práticas pedagógicas alternativas entre outras e que possam comprovar: 1) formação em cursos de licenciatura em Educação Especial ou em uma de suas áreas, preferencialmente de modo concomitante e associado à 
licenciatura para educação infantil ou para os anos iniciais do ensino fundamental; 2) complementação de estudos ou pós-graduação em áreas específicas da Educação Especial, posterior à licenciatura nas diferentes áreas do conhecimento, para atuação nos anos finais do ensino fundamental e no ensino médio" (p. 05).

Além disso, a Associação Nacional pela Formação dos Profissionais da Educação/Anfope ${ }^{2}$ (2002, p. 43-44) determina que a formação dos docentes e gestores educacionais deve estar voltada para:

- formação teórica e interdisciplinar, considerando os fundamentos históricos, políticos e sociais que lhes dão sustentação;

- compreensão de teoria e prática, em busca de uma apropriação de saberes que forme para os pensares e fazeres, contrapondo-se à cisão do indivíduo e à formação fragmentada;

- gestão democrática, transparente, responsável e crítica, como possibilidade de luta contra a constituição de qualquer tipo de ação autoritária e, consequentemente, centralizadora e excludente;

- compromisso social com a formação profissional dos trabalhadores da educação, com ênfase nos aspectos sociopolíticos e históricos presentes na concepção revolucionária de indivíduo educador, sem abrir mão, banalizar ou reduzir o atendimento da demanda humana desses trabalhadores;

- trabalho coletivo e interdisciplinar entre diferentes pensares, saberes e fazeres, ou seja, entre diversas e diferentes subjetividades, como categoria central de nossa atuação política;

- avaliação crítica e reflexiva permanente, entendida como método de trabalho coletivo, responsável e com potencial emancipador para professores e alunos.

A implementação das previsões desses dispositivos legais representa um desafio à formação docente no que se refere aos cursos de Pedagogia, pois a formação do docente/pedagogo não deve ser dissociada da produção dos saberes e fazeres dos contextos científico, filosófico e político da diversidade humana. Portanto, a educação deve ser dirigida para a emancipação crítica, para a contradição e para a resistência às múltiplas formas da barbárie social que estão presentes na contemporaneidade, conforme aponta Adorno (1995, p. 150):

\footnotetext{
2 A comissão vinculada à Sesu (Secretaria do Ensino Superior do MEC), designada pela Portaria no 14 , de 06-03-98, era composta pelos seguintes membros: Leda Scheibe (presidente), Celestino Alves da Silva, Márcia Ângela Aguiar, Tizuko Morchida Kishimoto e Zélia Milléo Pavão.
}

Justamente na formação profissional do trabalhador necessita-se uma aptidão à experiência desenvolvida e um elevado nível de reflexão, para preservar-se em situações em permanente transformação e suportando aquilo que o senhor designou como "pressão do mundo administrado".

Nesse sentido, a formação é atravessada pelos mecanismos hegemônicos de "pressão do mundo administrado" (ADORNO, 1995), que impulsiona a razão instrumental da técnica, sob os moldes do capital, transformando o processo de formação em "pseudoatividade". Logo, essa dimensão do trabalho obstaculiza a reflexão do indivíduo enquanto ser social, impondo a lógica da sociedade de classes, que se expressa na heteronomia e na destituição da emancipação/ sensibilidade.

Segundo Costa (2015), a formação dos docentes é predominantemente influenciada pela reprodução social da adaptação e do mundo do trabalho, posto que é caracterizada pela padronização, homogeneização, conservadorismo e alheia ao contexto sociocultural e histórico. Assim, Adorno (1995, p.181) ressalta que:

Se atualmente ainda podemos afirmar que vivemos numa época de esclarecimento, isto tornou-se muito questionável em face da pressão inimaginável exercida sobre as pessoas, seja simplesmente pela própria organização do mundo, seja num sentido mais amplo, pelo controle planificado até mesmo de toda a realidade interior pela indústria cultural. Se não quisermos aplicar a palavra "emancipação" num sentido meramente teórico, ele próprio tão vazio como o discurso dos compromissos que as outras senhorias empunham frente à emancipação, então por certo é preciso começar a ver efetivamente as enormes dificuldades que se opõem à emancipação nesta organização de mundo [...] O motivo evidentemente é a contradição social; é que a organização social em que vivemos continua sendo heterônoma, isto é, nenhuma pessoa pode existir na sociedade atual realmente conforme suas próprias determinações; enquanto isto ocorre, a sociedade forma as pessoas mediante inúmeros canais e instâncias mediadoras, de um modo tal que tudo absorvem e aceitam nos termos desta configuração heterônoma que se desviou de si mesma em sua consciência.

Tal concepção demarca mecanismos que reforçam a sustentação das relações baseadas em preconceitos e mecanismos de exclusão, enfatizando o modelo hegemônico consolidado pelo capital. Dessa forma, há uma configuração alienante marcada pela barbárie, na qual a democracia é ocultada, visto que os mecanismos de exclusão social na manifestação do preconceito e da segregação são aumentados em prol da sustentabilidade 
do poder. Assim, a visão da burguesia industrial é a própria denominação da indústria cultural, cuja inserção no mundo provocou ações metamórficas na estrutura social e, consequentemente, nas relações humanas.

Dada a natureza do trabalho pedagógico docente, espera-se dos processos formativos o desenvolvimento dos conhecimentos aprofundados, a sensibilização de atitudes e a afirmação de valores que potencializem os(as) professores(as) na construção de saberes e fazeres diante dos desafios que a inclusão dos estudantes público-alvo da Educação Especial apresentam no cotidiano escolar.

Uma educação sem indivíduos é opressiva, repressiva. Mas quando procuramos cultivar indivíduos da mesma maneira que cultivamos plantas que regamos com água, então isto tem algo de quimérico e de ideológico. A única possibilidade que existe é tornar tudo isso consciente na educação (ADORNO, 1995, p. 154).

Dessa forma, os conhecimentos adquiridos no curso de Pedagogia devem ser pautados nas teorias da educação e do ensino, assim como nas áreas dos conhecimentos necessários à experiência na/para a diversidade, em que os docentes possam desenvolver suas práxis pedagógicas considerando seus saberes e fazeres na perspectiva da educação inclusiva. Nessa perspectiva, "será necessária uma sólida formação teórica dos futuros pedagogos/ professores, de forma a contribuírem efetivamente na busca de soluções para processos de escolarização, de pesquisa, de gestão e de diminuição dos índices de exclusão escolar" (BARRETO, 2009, p. 182).

Esse profissional deverá ter seu lócus prioritário de formação nas universidades, de forma que se permita a produção do conhecimento social, cultural e científico nas diferentes dimensões do saber e do permanente exercício crítico reflexivo na significação das práticas pedagógicas configuradas no cenário educacional. O curso de Pedagogia deverá incluir em seu repertório curricular a dimensão de conceitos relativos à diversidade e a diferença das subjetividades encontradas na sociedade, considerando as pessoas com deficiência, as etnias, as religiões, os gêneros, entre tantas outras singularidades humanas. Portanto, "a consciência de todos em relação a essas questões poderia resultar dos termos de uma crítica imanente, já que nenhuma democracia normal poderia se dar ao luxo de se opor de maneira explícita a um tal esclarecimento" (ADORNO, 1995, p. 183).

Ante o exposto, é nas vias formativas que a formulação dos conhecimentos irá permitir práticas pedagógicas que considerem o contexto social e as singularidades, levando em conta a diversidade e as diferenças que compõem o espaço escolar e criando mecanismos que visem à instituição de uma cultura inclusiva, adequada ao trabalho profissional do pedagogo/professor. Daí, é no sentido de possibilitar ao docente a reflexão do todo (teoria e prática) nos cursos de Pedagogia, sobre os condicionantes globais do trabalho pedagógico e inclusivo no âmbito escolar, que se afirma que "não existe prática sem teoria; como também não existe teoria sem prática, porque o importante é que a reflexão seja um instrumento dinamizador entre prática e teoria" (FREIRE, 1996, p. 39).

Assim, não se ignoram os desafios postos no campo das políticas públicas para a formação dos professores nos cursos de Pedagogia, sobretudo quando as Diretrizes Curriculares Nacionais para o Curso de Pedagogia (BRASIL, 2006) determinam, no artigo 10, que o profissional pedagogo/docente deve "[...] demonstrar consciência da diversidade no que diz respeito às diferenças de natureza ambiental-ecológica, ético-racial, de gêneros, faixas geracionais, classes sociais, religiões, necessidades especiais, escolhas sexuais, entre outras".

A partir de tal perfil, a formação dos docentes no curso de Pedagogia deve ser organizada de forma a contemplar a diversidade humana em uma perspectiva global, tendo em vista "o desenvolvimento da sensibilidade dos professores, para que eles possam pensar o planejamento e executar a prática pedagógica levando em consideração a demanda de seus alunos, considerando novas possibilidades de atuação junto a eles" (COSTA, 2007, p. 29).

Nessa direção, o desenvolvimento profissional dos docentes para a diversidade não deve mais ser baseado na reprodução de saberes/práticas cristalizados espaçotemporalmente, que invariavelmente estão atrelados às formas de discriminação que imperam na sociedade. Pois, sobre a exclusão vigente aos moldes da barbárie, vale recorrer a Adorno (1995, p. 155), quando constata que:

[...] desbarbarizar tornou-se a questão mais urgente da educação hoje em dia. O problema que se impõe nesta medida é saber se por meio da educação pode-se transformar algo de decisivo em relação à barbárie. Entendo por barbárie algo muito simples, ou seja, que, estando na civilização do mais alto desenvolvimento tecnológico, as pessoas se encontrem atrasadas de um modo peculiarmente disforme em relação a sua própria civilização - e não apenas por não terem em sua arrasadora maioria experimentado a formação nos termos correspondentes ao conceito de civilização, mas também por se encontrarem tomadas por uma agressividade primitiva, um ódio primitivo ou, na terminologia culta, um impulso de destruição, que contribui para aumentar ainda mais o perigo de que toda esta civilização venha a explodir, aliás uma tendência imanente que a caracteriza. Considero tão urgente impedir isto que eu reordenaria todos os outros objetivos educacionais por esta prioridade.

O pensamento do referido autor alerta para os desafios que se fazem presentes na sociedade e na escola através 
dos mecanismos de exclusão, preconceito, segregação e na busca de uma formação docente que rompa com os ditames da "ditadura da barbárie" na cultura hodierna, marcada fortemente pela concepção hegemônica da autocracia. Dessa forma, uma formação emancipada e crítica possibilita ao indivíduo se esclarecer sobre as contradições vividas na sociedade sob a égide da formação capitalista, rompendo com os modelos técnicos dominantes.

Para que essa formação crítica se efetive nos cursos de Pedagogia, é necessária a concretização de contextos formativos que visem à superação dos moldes impostos na sociedade administrada (ADORNO, 1995), sobretudo rompendo com a ideologia vigente em um sentido formativo autêntico, autocrítico e autorreflexivo, capaz de se opor à dominação. Segundo essa concepção, Costa (2005, p. 67) possibilita o pensar sobre a atribuição docente com vistas ao seu papel profissional, no que tange à Educação Especial, ao constatar que:

Diante dessa possibilidade, a questão posta aos profissionais que atuam na educação dos alunos com deficiência é: não é o momento de pensar a própria concepção de educação especial, uma vez que ela contém a ideia de discriminação, de segregação, de barbárie, de exclusão escolar, social e cultural dos alunos com deficiência denominados 'especiais', ou seja, inadaptados, desiguais? Pensar sobre isso pode ser revolucionário, pois 'aquele que pensa opõe resistência'.

O professor deve ter consciência de seu papel, que vai para além da manutenção de práticas antidemocráticas e autocráticas que aprisionam os estudantes em padrões do mundo moderno, homogeneizando-os. Em consonância com essa análise, Adorno (1995, p. 121) afirma que:

[...] é necessário o que a esse respeito uma vez denominei de inflexão em direção ao sujeito. É preciso reconhecer os mecanismos que tornam as pessoas capazes de cometer tais atos, é preciso revelar tais mecanismos a eles próprios, procurando impedir que se tornem novamente capazes de tais atos, na medida em que se desperta uma consciência geral acerca desses mecanismos. Os culpados não são os assassinados, nem mesmo naquele sentido caricato e sofista que ainda hoje seria do agrado de alguns. Culpados são unicamente os que, desprovidos de consciência, voltaram contra aqueles seu ódio e sua fúria agressiva. É necessário contrapor-se a uma tal ausência de consciência, é preciso evitar que as pessoas golpeiem para os lados sem refletir a respeito de si próprias. A educação só tem sentido unicamente como educação dirigida a uma auto-reflexão crítica.

Diante dessas constatações, o curso de Pedagogia tem um papel determinante no enfrentamento dos desafios que se impõem na formação do professor para a diversidade, visto que a reflexão política e filosófica sobre o pedagogo/docente que se quer formar implica um conjunto de reformulações de conhecimentos e atitudes que permitam o desenvolvimento da crítica e da reflexão. E possibilitem-lhe também se libertar das amarras das forças massificadas da segregação e da exclusão presentes nas instâncias sociais, sobretudo no esclarecimento formativo de si mesmo.

A emancipação é uma condição sine qua non para a efetivação da democracia na formação do indivíduo reflexivo, crítico e autônomo. E para uma sociedade se democratizar, em que a equidade não seja ultrajada pelos processos discriminatórios, é necessário fortalecer os direitos constituídos nas políticas públicas na/da educação dos estudantes, com e sem deficiências, considerando legitimamente a diversidade humana.

Os movimentos da inclusão revelam a possibilidade de se elaborar novas/outras reflexões a respeito do pedagogo/docente que se quer formar, sobretudo na conscientização de práticas educativas plurais com vistas à inclusão dos estudantes público-alvo da Educação Especial. E pode-se constatar que os docentes devem se conscientizar de seu papel no âmbito educacional diante das novas demandas da diversidade que se fazem nas políticas públicas. De tal modo que a formação não se paute pelo mecanismo da ausência de emancipação crítica em uma categoria estática, mas por uma categoria dinâmica (ADORNO, 1995), sendo propriamente a formação em seu devir.

O essencial é pensar a sociedade e a educação em seu devir. Só assim seria possível fixar alternativas históricas tendo como base a emancipação de todos no sentido de se tornarem sujeitos refletidos da história, aptos a interromper a barbárie e realizar o conteúdo positivo, emancipatório, do movimento de ilustração da razão (ADORNO, 1995, p. 12).

Por conseguinte, e corroborando o pensamento de Adorno, uma formação para a diversidade só é possível na medida em que oportuniza constituir indivíduos essencialmente emancipados.

\section{CONSIDERAÇÕES FINAIS}

As políticas públicas de educação inclusiva, no contexto da Educação Especial, constituem-se numa instância humanística/democrática da sociedade, compreendendo as diferenças e (re)estruturando as práticas pedagógicas com vistas à afirmação de um processo de ensino-aprendizagem adequado às necessidades de todos os estudantes, com ou sem deficiência, no cenário escolar. 
A emancipação do pensar torna-se indispensável para a formação crítica dos docentes/pedagogos, objetivando uma formação para a sensibilização, para o reconhecimento da diversidade humana. Nesse sentido, a consolidação das políticas educacionais inclusivas só estará efetivada se a formação do pedagogo/docente promover experiências teóricas consolidadas na práxis pedagógica inclusiva, reconhecendo o caráter dinâmico (teoria e prática) da escola e sua diversidade cultural e humana. Adorno (1995, p. 151) reforça esse entendimento quando afirma:

Mas aquilo que caracteriza propriamente a consciência é o pensar em relação à realidade, ao conteúdo, à relação entre as formas e estruturas de pensamento do sujeito e aquilo que esse não é. Esse sentido mais profundo de consciência ou faculdade de pensar não é apenas o desenvolvimento lógico formal, mas ele corresponde literalmente à capacidade de fazer experiências. Eu diria que pensar é o mesmo que fazer experiências intelectuais. Nesta medida e nos termos que procuramos expor, a educação para a experiência é idêntica à educação para a emancipação.

A visão do referido autor revela que o pensar é para além das experiências, uma vez que não obscurece a razão da consciência, mas a emancipa nas formas e estruturas de pensamento do indivíduo, isto é, numa orquestração entre o pensar, humanizar e se esclarecer. Pois "é no olhar para o desviante, no ódio à banalidade, na busca do que ainda não está gasto, do que ainda não foi capturado pelo esquema conceitual geral, que reside a derradeira chance do pensamento" (ADORNO, 1993, p. 58).

Para tanto, o ato de incluir pressupõe uma superação dos preconceitos vigentes na sociedade, sobretudo rompendo com uma consciência massificada por estigmas, o que provoca uma dessensibilização dentro e fora das escolas. Quanto a essa questão da reprodução das estruturas vigentes na sociedade marcadas por preconceitos, Adorno (1995, p. 170) menciona:

[...] Para nos expressarmos em termos corriqueiros, isto não significa emancipação mediante a escola para todos, mas emancipação pela demolição da estruturação vigente em três níveis e por intermédio de uma oferta formativa bastante diferenciada e múltipla em todos os níveis, da pré-escola até o aperfeiçoamento permanente, possibilitando, deste modo, o desenvolvimento da emancipação em cada indivíduo, o qual precisa assegurar sua emancipação em um mundo que parece particularmente determinado a dirigi-lo heteronomamente, situação que confere uma importância ainda maior ao processo.

Portanto, fica notório que desbarbarizar tornouse crucial na educação e nos moldes contemporâneos, no sentido de reafirmar as estruturas organizacionais antidemocráticas na contemporaneidade. A formação dos pedagogos/docentes demanda uma práxis políticopedagógica que os faça refletir sobre seus saberes e fazeres, a fim de romper com a práxis ilusória marcada pela racionalidade técnica vigente. Conforme afirmado por Adorno (1995), educação é o mesmo que emancipação, sobretudo conscientização e racionalidade.

\section{REFERÊNCIAS}

ADORNO, Theodor Wiesengrund. Educação para emancipação. São Paulo: Paz e Terra, 1995.

Palavras e sinas: modelos críticos 2. Petropólis, RJ: Vozes, $1995 \mathrm{a}$.

Teoria da semicultura. In: Educação e Sociedade, Campinas, n. 56, p. 388-411, dez. 1996.

Minima moralia. Trad. de Luiz Eduardo Bicca. 2. ed. São Paulo: Ática, 1993.

BRASIL. Constituição da República Federativa do Brasil. Brasília, 1988.

Lei de Diretrizes e Bases da Educação Nacional. Lei no 9394/96, de 20 de dezembro de 1996.

. Câmara da Educação Básica. Resolução CNE/CEB $\mathrm{n}$ o 2, de 11 de setembro de 2001. Institui Diretrizes Nacionais para a Educação Especial na Educação Básica. Brasília, DF, 2001.

Conselho Nacional de Educação. Resolução no 1, de 15 de maio de 2006. Institui Diretrizes Curriculares Nacionais para o Curso de Graduação em Pedagogia, Licenciatura. Brasília, DF, 2006.

Ministério da Educação. Secretaria de Educação Especial. Política Nacional da Educação Especial na Perspectiva da Educação Inclusiva. Brasília: MEC/Seesp, 2008.

. Ministério da Educação. Lei no 13.005, de 25 de junho de 2014. Aprova o Plano Nacional de Educação e dá outras providências.

BARRETO, Maria Aparecida Santos Corrêa. As políticas de formação do professor e a construção de processos educativos inclusivos: dilemas e possibilidades. In: BAPTISTA, Claudio Roberto; JESUS, Denise Meyrelles de (Org.). Avanços em políticas de inclusão: o contexto da educação especial no Brasil e em outros países. 2. ed. Porto Alegre: Mediação, 2009. p. 175-189.

COSTA, Valdelúcia Alves da. Formação e teoria crítica da Escola de Frankfurt: trabalho, educação, indivíduo com deficiência. Niterói, Eduff, 2005.

Os processos de inclusão dos alunos com necessidades educativas especiais: políticas e sistemas. Rio de Janeiro: Unirio/Cead, 2007.

. Formação de professores e sua relação com a educação inclusiva: desafios à experiência teórica na práxis pedagógica. Revista Educação Especial, Santa Maria, v. 28, n. 52, p. 405-416, maio/ago. 2015. Disponível em: <http://dx.doi. org/10.5902/1984686X9628>. Acesso em: 15 fev. 2016. 
CONSELHO NACIONAL DE EDUCAÇÃO. A Declaração de Bolonha e o sistema de graus no ensino superior. Bolonha, 2002. Disponível em: <https://dre.pt/application/file/1817968>. Acesso em: 15 mar. 2015.

DAMASCENO, Allan Rocha. Educação inclusiva e organização da escola: projeto pedagógico na perspectiva da teoria crítica. Tese (Doutorado em Educação) - Programa de Pós-Graduação em Educação, Faculdade de Educação, Universidade Federal Fluminense. Rio de Janeiro, 2010.

Educação inclusiva e a organização da escola: perspectivas críticas e desafios políticos do projeto pedagógico. Rio de Janeiro: Abrace um aluno escritor/Capes, 2015.

FREIRE, Paulo. Pedagogia da autonomia: saberes necessários à prática educativa. 23. ed. São Paulo: Paz e Terra, 1996.

FIGUEIREDO, Rita Vieira de. A formação de professores para a inclusão dos alunos no espaço pedagógico da diversidade. In: MANTOAN, Maria Teresa Égler (Org.). O desafio das diferenças nas escolas. 3. ed. Petrópolis, RJ: Vozes, 2011. p. 141-145.
LIBÂNEO, José Carlos; PIMENTA, Selma Garrido. Formação dos profissionais da educação: visão crítica e perspectivas de mudança. In: PIMENTA, Selma Garrido (Org.). Pedagogia e pedagogos: caminhos e perspectivas. 2. ed. São Paulo: Cortez, 2006.

PEÇAS, Américo. Uma escola acolhedora, uma educação inclusiva. In: LINHARES, Célia; TRINDADE, Maria Nazaret (Org.). Compartilhando o mundo com Paulo Freire. São Paulo: Cortez, 2003.

SANTOS, Boaventura de Souza. Por que é tão difícil construir uma teoria crítica? In: Revista Crítica de Ciências Sociais, Faculdade de Economia da Universidade de Coimbra e Centro de Estudos Sociais. n. 54, jun. 1999. Disponível em: $<\mathrm{http}$ //www.boaventuradesousasantos.pt/pages/pt/artigos-emrevistas-científicas.php>. Acesso em: 29 ago. 2014.

UNESCO. Declaração de Salamanca e suas linhas de ação sobre necessidades educacionais especiais. Brasília: Corde, 1994.

Submetido em 16-06-2016.

Aprovado em 15-02-2017. 